\title{
Sustainable Cities: A Proposed Environmental Integrity Index (EII) for Decision Making
}

\author{
Shagufta T. Shathy and Mohammad I. H. Reza* \\ Southeast Asia Disaster Prevention Research Initiative, Institute for Environment and Development (LESTARI), Universiti \\ Kebangsaan Malaysia, Bangi, Malaysia
}

\section{OPEN ACCESS}

Edited by:

Alesia Coralie Ferguson

University of Arkansas for Medical

Sciences, USA

Reviewed by:

Oluyinka Oyewumi,

Central Connecticut State University,

USA

Marco Casazza

Parthenope University of Naples, Italy

*Correspondence:

Mohammad I. H. Reza

rezamih@gmail.com;

reza@ukm.edu.my

Specialty section:

This article was submitted to

Environmental Health,

a section of the journal

Frontiers in Environmental Science

Received: 19 August 2016 Accepted: 12 December 2016 Published: 26 December 2016

Citation:

Shathy ST and Reza MIH (2016)

Sustainable Cities: A Proposed Environmental Integrity Index (EII) for

Decision Making.

Front. Environ. Sci. 4:82.

doi: 10.3389/fenvs.2016.00082
Urban population has been increasing at an unprecedented rate accommodating more than half of the world population in cities. Massive human intervention in the tropical region contributes to loss of environmental integrity amplifying challenges like air pollution, deforestation, water scarcity, local extinction, and destruction of natural landscapes. To shape the international community's attitude toward economic, social, and environmental development regarding environmental integrity different methods- Reducing Emissions from Deforestation and Forest Degradation (REDD+), Clean Development Mechanism (CMD) - are introduced. However, these methods have some limitations along with opportunities. This paper reviewed and analyzed existing methods in order to promote environmental integrity in the rapidly growing urban settings. Based on the drawbacks of current methods a new Environmental Integrity Index (EII) is proposed where indicators are selected while considering social, economic, and environmental aspects. The index aims to combine data from field surveys, GIS and remote sensing, and economic and social analysis. We anticipate that this proposed index can support planning for sustainable cities by promoting environmental integrity and balancing biological and ecological components in a highly intricate urban system.

Keywords: sustainable cities, sustainable urban planning, decision support system, sustainability indicators, urban climate, Southeast Asian landscapes

\section{INTRODUCTION}

Urban population has been increasing at an unprecedented rate accommodating more than half of the world's population in cities (United Nations, 2014). Although countries with good infrastructure manage the pace of urban growth in a good manner, developing countriesmainly in Asia-face various social, economic, and environmental challenges associated with rapid urbanization (Sridhar and Wan, 2014). Among the difficulties faced by the fastest growing developing countries are a range of environmental problems, which are manifested in terms of pollution, traffic congestion, and other public health issues (Cohen, 2006). These anthropogenic activities consequently impact the environmental equilibrium by creating fragmentation, changing the urban climate and increasing hazards to human health.

Globally, cities are increasingly facing many environmental health challenges including air and water pollution, contamination of soil, traffic congestion, noise, and poor housing structures that are exacerbated by unsustainable city and country planning and urban development schemes (Vardoulakis et al., 2016). Due to the global environmental change resulting from an increase in 
the frequency and intensity of extreme weather events (e.g., heat waves, tropical cyclones, and heavy rainfall), and increasing anthropogenic disturbance (e.g., forest fires, deforestation, and illegal logging), the detrimental effects of such phenomena are also playing a role in changing the ecological balances in the urban settings (Heal et al., 2013). Additionally, these processes are also exacerbating urban heat island effects (Heaviside et al., 2015) thereby increasing energy consumption and ultimately affecting public health (Vardoulakis et al., 2015).

Researchers around the world have suggested initiatives to deal with these effects. Some have engaged stakeholders for collaborative assessments in identifying the causal agents for urban complexities (Macmillan et al., 2016), while others have conducted surveys for a new approach to address the complexities that worsen urban environmental health (Nieuwenhuijsen, 2016). Woods et al. (2016) demonstrated a multi-criteria decision analysis to prioritize environmental health hazards in a city, while Salmond et al. (2016) valued ecosystem services as an alternative approach. The approach used by Tulloch et al. (2015) for threat mapping may also be applied toward finding a solution in planning for a sustainable city by minimizing the increasing threats to that region. Ecological integrity has become a popular approach for sustainable management purposes (Westra et al., 2000; Borja et al., 2009). Ecological integrity is used to measure the ecological condition of an environment (Andreasen et al., 2001; Hargiss et al., 2008). Despite these varied approaches, no multi-metric integrated index exists to measure the degree of environmental changes and state of the environmental integrity of an urban area. Consequently, most of the developing countries are neither in a position to understand the level of environmental integrity in the city nor can they project their future environmental state. As a result, all manner of people from the general public to the policy maker do not understand the importance of a balanced system required for a sustainable city. To address this issue, this paper aims to propose an Environmental Integrity Index (EII) to measure the urban environmental health of a city.

At first, this study discusses the trends and facts regarding the urbanization processes and their relationships to environmental health. Then, sustainable urban development (SUD) goals of some selected countries with local policy trends are documented. An attempt has been made to show the relevance of the global agenda with local sustainable planning mechanism by describing and comparing the environmental indicators of different countries and the United Nations Centre for Human Settlements (UNCHS). Finally, this study demonstrates a step by step measuring criteria for an EII to examine the urban environmental health of a city. Here the study showcases how an index can be developed and the sets of indicators that are best selected for a comprehensive index. We believe that this index will help decision makers plan for sustainable city development. The novel approach taken here is the integration of familiar indicators in a systematic selection procedure to measure the environmental changes taking place in an urban context.

\section{BACKGROUND}

\section{Ecological Consequences of Urbanization}

Urbanization is one of the most visible anthropogenic forces which results in the horizontal and vertical growth of areas with a dense population (Dawson et al., 2007; Rydin et al., 2012). Cities are important drivers of social and economic transformation which help in geographic mobility-linking rural areas and international borders leading to lower fertility and longer life expectancy (United Nations, 2014). In 1800, only 3 percent of the world's populations were living in urban residences as compared to 14 percent in 1900 (Figure 1, Davis, 1955; United Nations, 2012). At present, the world is experiencing the largest wave of urban growth in history, accommodating more than half of the world's populations in towns and cities. Worldwide, 54 percent of the people are residing in urban areas and the projected world urban population will be 66 percent of the total population by the end of 2050 (United Nations, 2014, Figure 1). While the world has experienced mass urbanization in the past, at the current trend, it is estimated that 96 percent of urbanization will be realized in the developing world by 2030 (United Nations, 2012). Out of the top 10 most densely populated megacities, seven of them are in the Asia Pacific region (United Nations, 2014). At the beginning of the 20th-century, the total number of cities in the world was 16 . However, at present, the total number of cities is around 400 (Cohen, 2006). Due to the rapid expansion of cities, sustainable management has become increasingly complex for environment, natural resources, and health conditions for both human and the environmental system (Cohen, 2006).

\section{Sustainable Urban Development (SUD) and Indicators}

Social, economic, and environmental challenges associated with rapid urbanization are considered one of the predominant factors for the growing interest in sustainable urban development (Deakin et al., 2002). The concept of sustainable development has been introduced in response to increasing awareness of social, economic, and environmental problems rooted in developmental activities. However, establishing a shared understanding of SUD is challenging due to its multi-dimensional nature (BEQUEST, 2000). The concept of sustainability has become integrated with urban design, and achieving sustainability in this field will provide environmental quality, and social and economic benefits (Dias et al., 2014). The sustainable city, according to the $\mathrm{UN}$, is one where long-lasting social, economic, and environmental developments are achieved (Porio, 2014). Li et al. (2009) explained this concept as the integrated development of social, economic and ecological systems through which economic balance, social progress, and environmental protection will be ensured. A symbiotic report generated by Sweden stated that SUD aims to create resilient and sustainable urban environment which also takes poverty reduction and improvement of livelihoods into consideration (Ranhagen and Groth, 2012).

Due to rapid sprawl, sustainable urban development has become a common goal for both developed and developing countries (May et al., 2000). Therefore, with the aim of urban sustainability and awareness of urban problems, development 


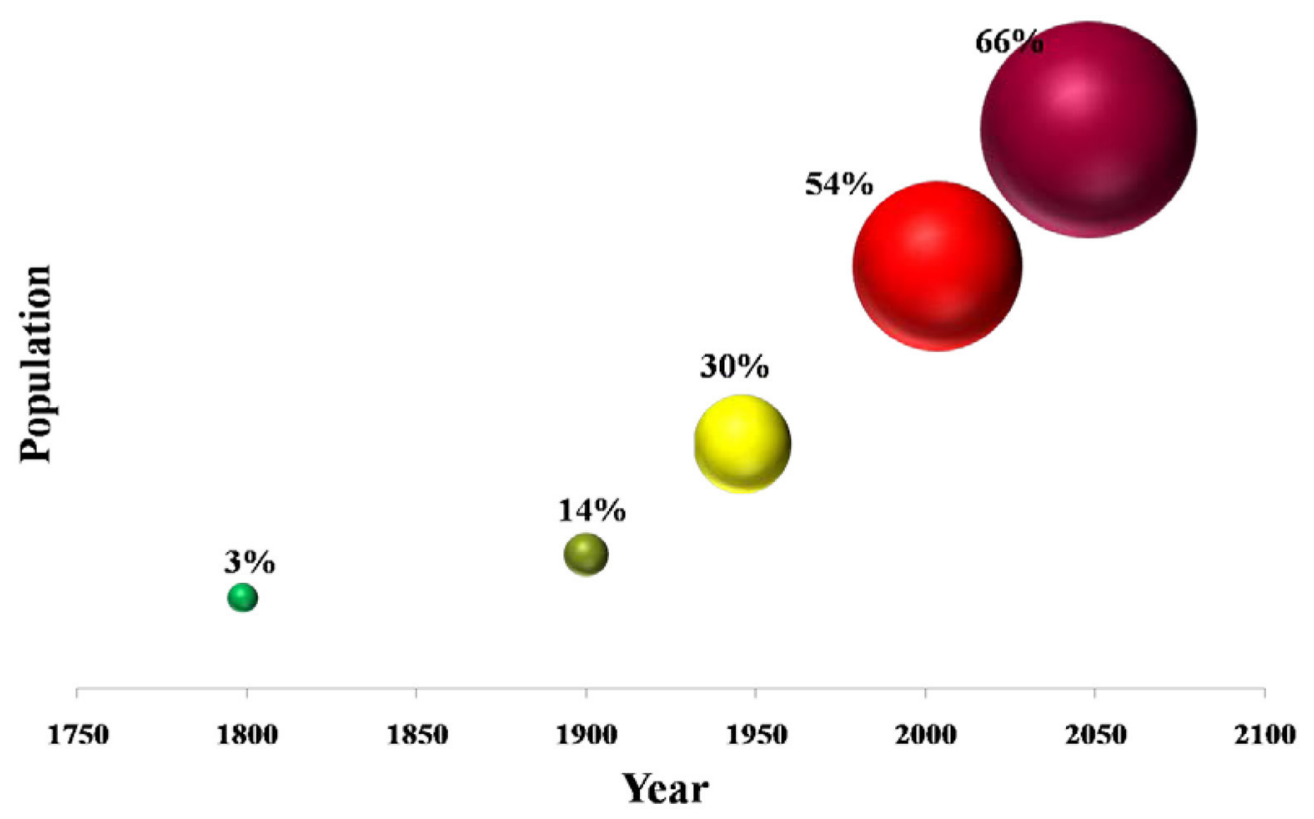

FIGURE 1 | Global urban population trend (Data source: United Nations, 2014).

of sustainable indicators is identified as a principal task for land managers (Chen and Wang, 2014). The significance of sustainable indicators (SIs) are that they can assess the ability of a system to withstand changes in long-term functioning (Milman and Short, 2008). They are the prerequisite for the implementation of SUD goals and assists in highlighting key issues at the local level (United Nations Development Programmes, 2006). Moreover, policy making at the local level, project management at the regional level, and financing in an international arena are some aspects of the usefulness of SIs (Michael et al., 2014). The initial urban indicators were set by the United Nations Centre for Human Settlements (UNCHS) in 1993 (UN Habitat, 2009). Later, various countries started establishing their indicators by adopting those set by the UNCHS and adding new indicators based on their own challenges, approach, and priorities (Newman and Kenworthy, 1999; Zavadskas et al., 2005; Bell and Morse, 2008). In line with the UNCHS, the Melbourne city council developed a city model named Melbourne 2030, while the Mexico City government introduced the Mexico City's Green Plan to achieve a sustainable city within next seven years (Yigitcanlar et al., 2008). The Melbourne city model stands out to be among one of the most successful development projects since this city was selected as the most livable city in the world in 2013 (Holden and Scerri, 2013).

\section{Countries SUD Goals}

Urbanization and urban growth, at present, are quite visible in developing countries, but city development plans considering SUD goals are not significant. As a result, fast urbanizing developing countries are facing problems such as poor city lives, poorly managed city development, and over population along with other adverse social, economic and environmental issues.
There are some developing countries such as Malaysia and China which have developed SUD goals and are in the process of implementation (Shamsuddin and Rashid, 2013; Li et al., 2014). However, except for a few developing countries, a majority of them are not following, or are unable to support SUD strategies due to over population and high poverty rates (Ichimura, 2003). To illustrate, the SUD goals set by three countries-Malaysia, China, and Australia-are compared with those of Latin America and UNCHS in Table 1.

Since urbanization is an on-going long term interdependent process between social, economic, and environmental development, environmental changes to support urban economy causes an imbalance in the entire ecological system (Ichimura, 2003; Omar, 2009). The goal of sustainable urban development is to monitor and regulate urbanization using some indicators (Li et al., 2009). At present, environmental challenges caused by urbanization are being highlighted due to their detrimental ramifications on human lives and the environmental system (Masakazu, 2003). Table 2 compares different environmental indicators set by different countries against those of the UNCHS. From the table, it is depicted that environmental indicators vary from country to country based on their challenges, approaches and priorities. However, the principal goal of all the indicators is to monitor the changes taking place in the urban environment. Countries have developed multiple indexes to assess those indicators, For instance, all the countries mentioned in Tables 1, 2 have their own air and water quality index to indicate the level of cleanliness of these two environmental components. Despite having numerous individual composite indicators or indexes, an integrated index for assessing the overall urban environmental condition of an urban area is yet to be proposed. 
TABLE 1 | Sustainable Urban Development (SUD) goals set by different countries and UNCHS.

\begin{tabular}{|c|c|c|c|c|c|}
\hline No. & UNCHS 2013 & Malaysia & China & Australia & Latin America \\
\hline 1 & Shelter & $\begin{array}{l}\text { Optimal use of land and } \\
\text { natural resources }\end{array}$ & Built environment & $\begin{array}{l}\text { Empower inclusive, productive and resilient } \\
\text { cities }\end{array}$ & \\
\hline 3 & $\begin{array}{l}\text { Environmental } \\
\text { Management }\end{array}$ & $\begin{array}{l}\text { Sustainable environmental } \\
\text { quality }\end{array}$ & Cleanliness & $\begin{array}{l}\text { Curb human-induced climate change, including } \\
\text { through an affordable and sustainable } \\
\text { low-emissions energy system } \\
\text { Ensure water is managed to sustain people } \\
\text { and the environment }\end{array}$ & $\begin{array}{l}\text { Air Quality Sanitation } \\
\text { Waste Water }\end{array}$ \\
\hline 4 & Economic development & Competitive economy & Economic development & Achieve a sustainable and inclusion economy & \\
\hline 5 & Governance & Effective governance & & Governance & Environmental governance \\
\hline 6 & & $\begin{array}{l}\text { Efficient infrastructure and } \\
\text { transportation }\end{array}$ & & & Transport \\
\hline
\end{tabular}

\section{METHODOLGY}

The environment consists of processes occurring within each element of soil, water, air, energy (example: decomposition process), and also interactions (example: interaction between soil and water) among these components. Currently, the main challenge facing humans is to understand how these processes and interactions are being affected by anthropogenic activities in order to preserve environmental integrity under changing conditions. Environmental integrity of an urban area includes urban environmental health, sustainability, diversity, resilience, and purity of natural communities within that environment. EII will be an approach for highlighting the loop holes in the urban system and identifying environmental challenges. The conceptual framework (Figure 2) proposed in this paper is general and can be appropriately modified and implemented in regional and local urban contexts. It provides general methods to assess urban environmental health conditions and the level of its integrity. However, it is impossible to measure all the potential components of an urban environment since in most of the cases the problems and focus are area specific. Since this paper mainly concentrates on urbanization, the development of the composite index of the components that represent the urban environmental health is selected.

\section{Ecological Integrity vs. Environmental Integrity}

Karr and Dudley defined ecological integrity as the capacity to support and maintain the balanced and integrated ecosystem in a particular region (Karr and Dudley, 1981). Müller et al. (2000) stated that ecological integrity indicates the self-organization capacity. At present, ecological integrity has become a popular approach for measuring ecological condition. There have been many approaches to the development of an index of ecological integrity. For instance, Regional Index of Ecological Integrity
(RIEI) for terrestrial and aquatic systems (Reza and Abdullah, 2011), Terrestrial Index of Ecological Integrity (TIEI) for regional terrestrial system (Andreasen et al., 2001) or the indexes suitable for aquatic systems (Karr and Chu, 1999; Barbour et al., 2000) are some of the well-accepted indexes of ecological integrity. However, most of the ecological or biological integrity indexes are suitable for the large or specific region where natural systems are dominant (Andreasen et al., 2001; Reza and Abdullah, 2011). These indexes are not very convenient or suitable to measure the ecological or environmental integrity of a highly complex urbanized system due to the existence of many types of pollutions, complex landscape compositions, and complex synergies. On the contrary, a comprehensive multi-metric index is yet to be proposed for measuring the ecological or environmental integrity of the highly developed and complex urbanized areas. Therefore, an integrated index of environmental integrity is suitable to measure the urban environmental health for sustainable urban planning, and assist decision makers of the land development authority. To identify the indicators, we are linking ecological dimension with an environmental aspect which is vital in the urban context. The rationale for selecting environmental integrity instead of ecological integrity is mainly due to the nature of the focus area. The urban system has more artificial components than the natural system. Moreover, when environmental integrity is selected to measure this system, we need a multi-metric approach to measure the degree of disturbance in this scheme, such that the choices in selecting indicators get broader.

\section{Characteristics of the Index}

Integration of environment mainly represents the structural, functional, and compositional features of a system (Karr, 1981; Müller, 2005). Nevertheless, due to the complexity of index in most cases, assessments remain beyond the understanding of the public and the stakeholders (Reza, 2014a). Various indexes 
TABLE 2 | Environmental indicators set by different countries and UNCHS.

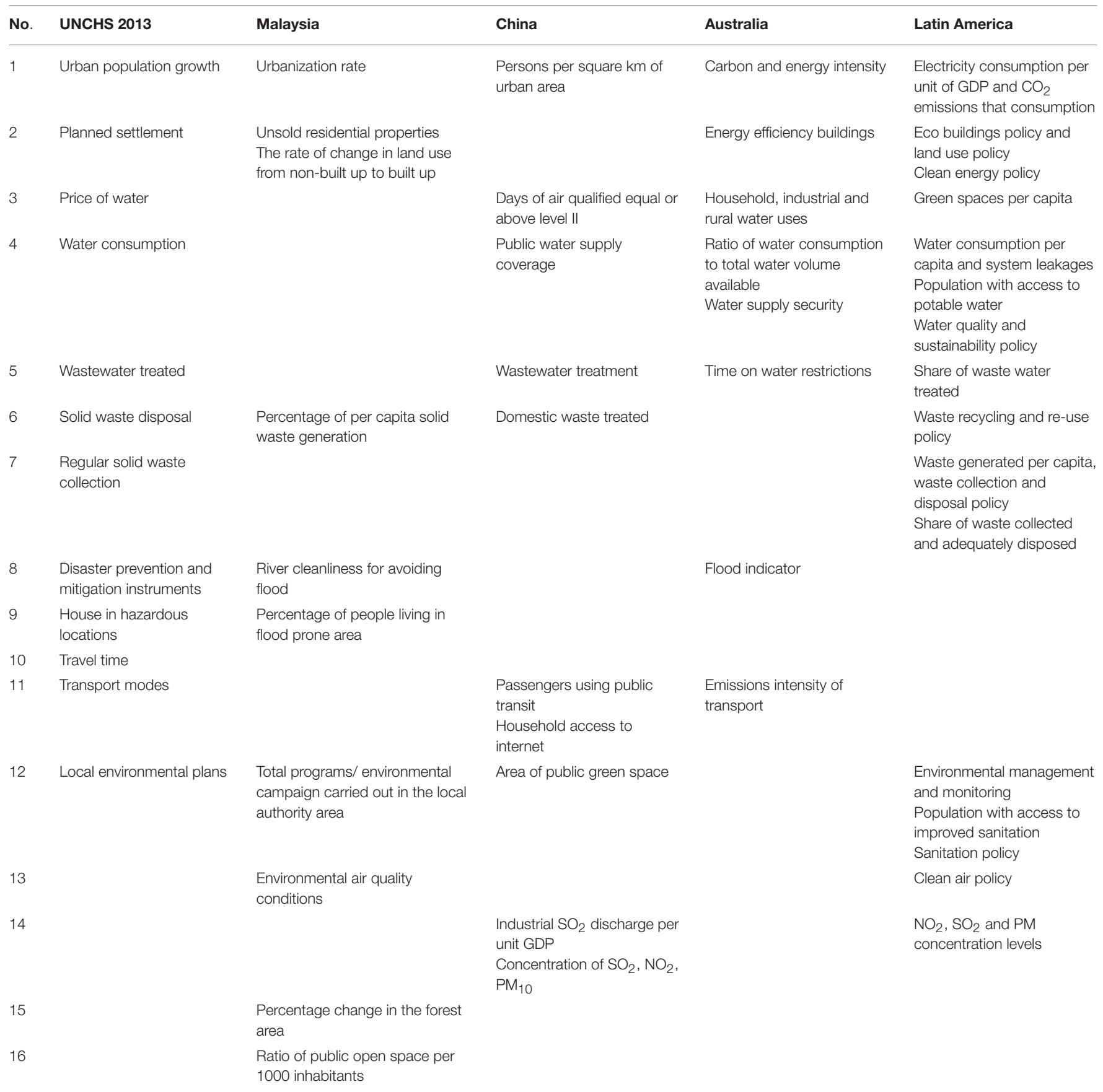

are taken into account to represent the diverse components of the environment to develop a composite index. An index of environmental integrity must describe the general characteristics of the urban environment. Therefore, the selection of indicators and their understanding by all stakeholders-decisions makers, urban planner and land managers-are equally important (Niemeijer and de Groot, 2008). The key features of our EII are multi-scaled, relevant and helpful, straightforward and flexible, adjustable and policy relevance (as proposed by Reza and Abdullah, 2011). Considering this factors, there remains significant room for improvement in the indicator selection process.

\section{Indicator Selection}

This section describes composite indicators for sustainable urban planning and development. Moreover, each indicator is composed of several sub-indices representing the type of land alternation and urban environmental health.

The application of indicators for environmental monitoring is an old practice, and they have been used for environmental 


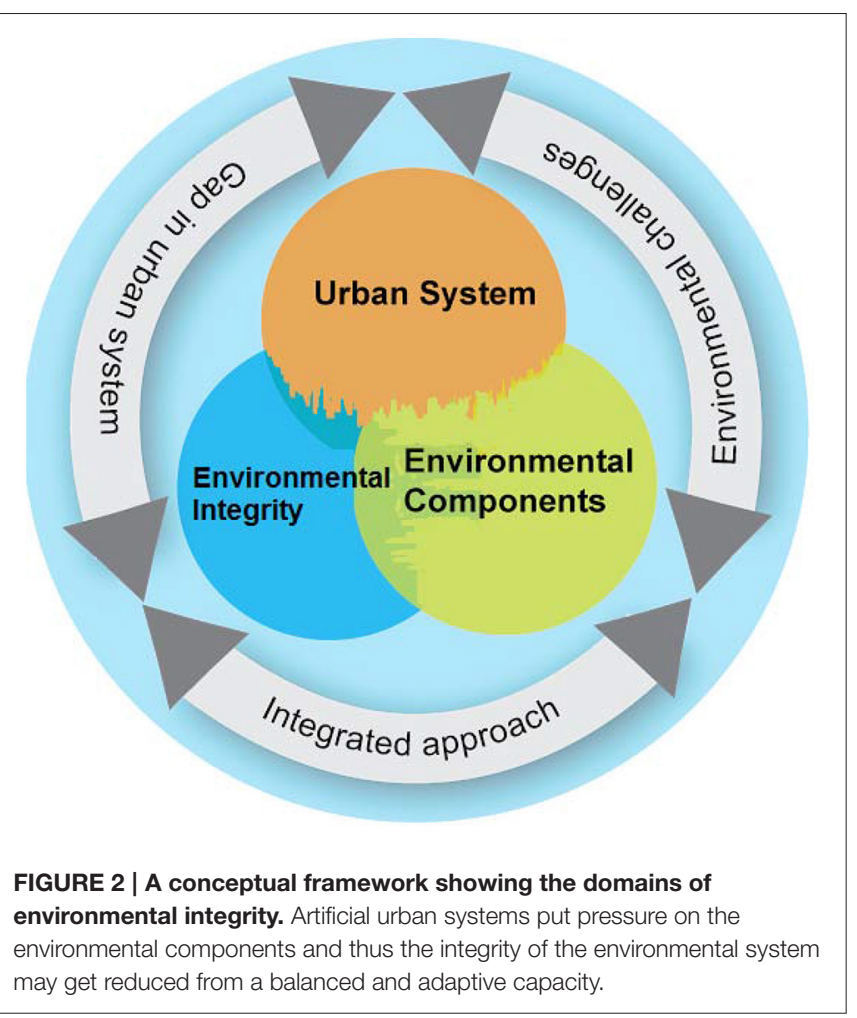

planning, policy making and mitigating emerging challenges rooted in urbanization (Zhou et al., 2015; Alam et al., 2016). Indicators are the empirical and indirect interpretations of reality to understand the dynamics of a system within a certain range of numerical values (Li et al., 2009; Alam et al., 2016). An index is established by integrating individual indicators, and the reason behind this integration is to combine a set of distinct concepts and variables on a single measurement scale (Tanguay et al., 2010). Therefore, the potential of an index primarily depends on the quality, relevance and availability of data on individual indicators. At present, multiple indexes-air and water quality index, ecological index, and human development index-exist, and they are being applied while focusing on different areas of interest. Apart from having different scale and application, the structural, methodological, and theoretical skeleton of all indexes are somewhat identical (Alam et al., 2016). In this study, the Pressure-State-Response (PSR) model has been developed to structure the conceptual framework (see Figure 3, Modified from OECD, 1994 and EEA, 2003). Here, the PSR model describes that, anthropogenic activities exert pressure on the environment and affect its natural integrity through changing the equilibrium and adequate proportion of its structural, compositional, and functional properties ("state"). While, society responds to these changes through environmental, technical means, economic measures and sectoral policies as well as through changes in attitudes and manners ("response"). In particular, the challenges associated with establishing cause-effect relationships between the boxes of the PSR framework suggest that it tends to simplify complex social, cultural, and ecological interactions (Levrel et al., 2009). Hence, the model approach fits with the themes-simple, measureable, and easy to assess for environmental integrity.

Sustainable urban development requires identification of suitable indicators to cope with the challenges associated with urbanization (Roche et al., 2014). Sustainability indicators are used to measure progress, discover problems, set development goals, and identify suitable management strategies (Zhou et al., 2015). Many researchers have been developing sustainability indicators consisting of economic, social, environmental, and political dimensions. For instance, Reza and Abdullah (2011) proposed RIEI summarizing ecological indicators into four categories-Fragmentation, Representativeness, Ecosystem sensitivity and Landscape connectivity. Here, from the environmental dimension, we consider three major components to evaluate the environmental integrity in an urban area (Table 3). Landscape Fragmentation represents the state of the anthropogenic development and direct pressures on the environmental integrity. Urban Climate denotes the flow and bio-geo-chemical cycles among the system. On the other hand the air and water quality index describe how the system can be polluted or changed due to the functions of human activities. All these indicators will be combined in a single index, and thus it describes the state of the environmental integrity of a given urban area.

\section{Landscape Fragmentation}

Landscape fragmentation is an important indicator used to calculate all human activities that are related to land (Forman, 1995). In many rapidly urbanized areas, landscape fragmentation has had severe impact leading to loss of biodiversity and ecosystem services, the result of which is unsustainable development (Abdullah and Nakagoshi, 2006). Fragmentation metric is mainly used to guide the decision maker to show the pattern of landscape changes. However, the main challenge of this metric is in understanding the mechanisms that caused the change. In our current study, we proposed a new method to analyze the spatially exact process of landscape fragmentation based on Forman's general model. In this research, fragmentation will be measured and analyzed spatially in a GIS platform.

The following section describes how Landscape Fragmentation can be measured in an urban setting. The remotely sensed image can be used successfully to measure fragmentation in the landscape and the regional level (Reza, 2014b). The following procedure can be used in the experimentation process.

Image processing: A map of land use and land cover need to be produced through satellite image processing. There are many online sources offering satellite imagery data (http://gisgeography.com/free-satellite-imagery-data-list/). For example:

(1) High-resolution image (i.e., 1-10 $\mathrm{m}$ resolution Spot, or Quick bird images) can be used to get information about buildings, trees/shrubs, grass, roads, parking lots, airports and water.

(2) Medium-resolution image [for example 30-90 m resolution Landsat Thematic Mapper (TM), or ASTER images] can 


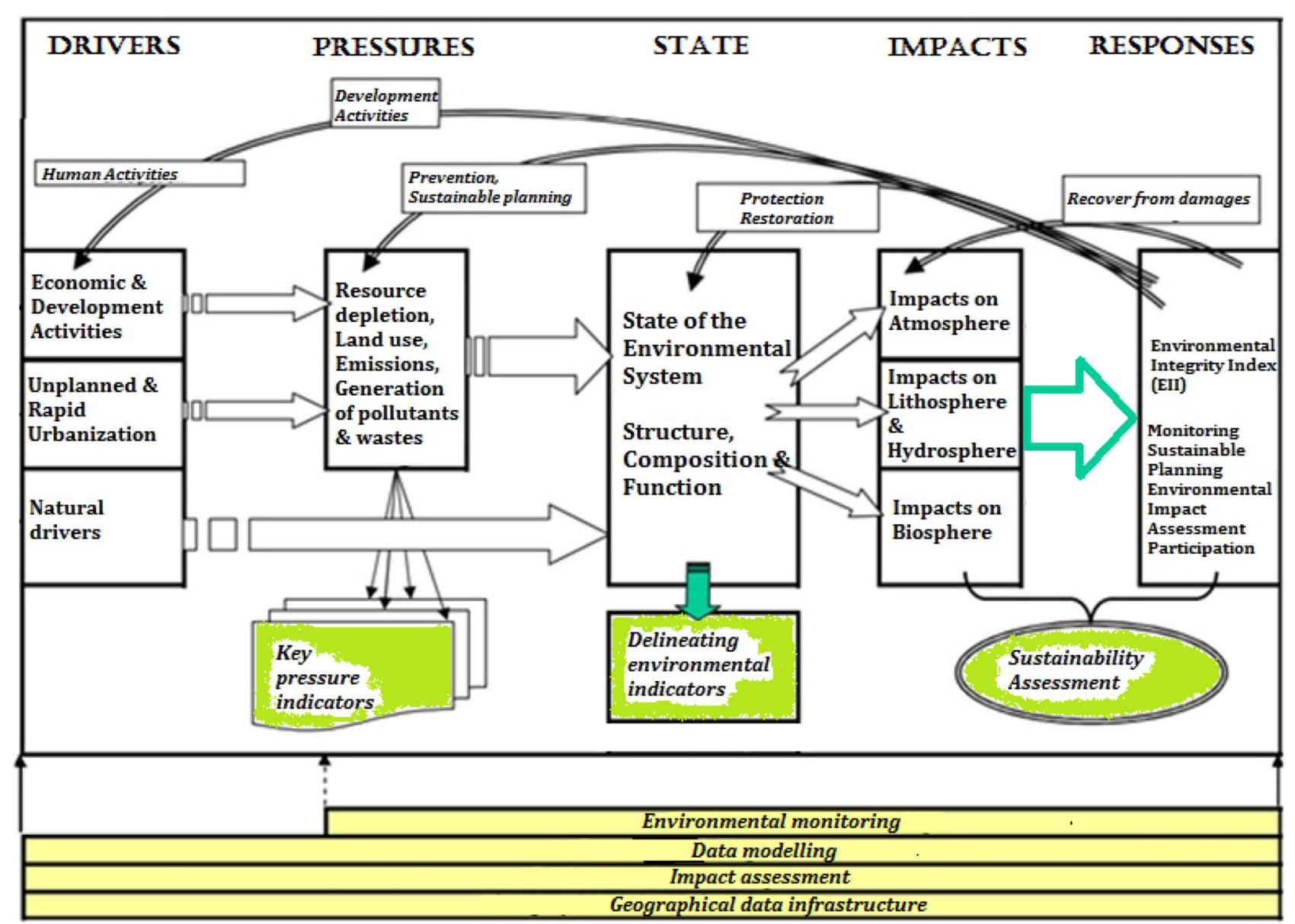

FIGURE 3 | A model of Pressure-State-Response showing how uncontrolled urbanization impacting environmental integrity. In response to these changes, an environmental integrity index (Ell) may have potential use for environmental monitoring and sustainable urban planning. (Modified from OECD, 1994 and EEA, 2003).

TABLE 3 | The indicators, sub-indicators and tools for the proposed Environmental Integrity Index (EII).

\begin{tabular}{lll}
\hline Major Indicator & Sub-indicators & Scale/ Tools \\
\hline Landscape Fragmentation & Urban landscape ratio, Infill, Extension & FRAGSTATS in Arc-GIS \\
Urban Climate & Surface temperature, Heat island, water body, vegetative cover & $\begin{array}{l}\text { Surface temperature map, Remotely sensed thermal infrared } \\
\text { technique }\end{array}$ \\
Vulnerability to Environmental Hazard & Water quality index, Air quality index & UNEPS proposed methodology \\
\hline
\end{tabular}

be used to examine the continuous urban landscape heterogeneity.

Data can be processed using ENVI, ERDAS, or eCognition in order to extract land use map by supervised/ unsupervised classification. After analyzing landscape patterns at different scales, data can further be combined using landscape level analyzing software. In this case, FRAGSTATS (version 4), v-LATE, or similar software can be used for raster and vector based data analysis.
A number of landscape fragmentation measuring indexes are available. However, a combination of indexes for measuring fragmentation of the urban landscapes can be proposed as follows:

(a) Urban landscape ratio (ratio of urban landscape area and build up area)

(b) Infill (development that occurred within urbanized open space)

(c) Extension (development of exterior open space) 
Urban Landscape Ratio (ULR): The ratio of total build up area and total urban landscape area in a given city. All types of build up areas-buildings, roads, parking lots and airports- are considered. Every pixel of land use map will be determined as either build up area or open space.

Numerical expression of Urban Landscape Ratio (ULR):

$$
\mathrm{ULR}=\mathrm{TBA} / \mathrm{TULA}
$$

$[\mathrm{TBA}=$ total build up area; TULA $=$ total urban landscape area]

Infill Ratio (IR): Development that occurred within urbanized open space within two different time periods. Here open space includes trees/shrubs, grass, and water body. Infill ratio is calculated as, the total development occurred within urbanized open space divided by total urbanized open space.

Numerical expression of Infill Ratio (IR):

$$
\mathrm{IR}=\mathrm{DUOS} / \mathrm{TUOS}
$$

[DUOS $=$ Development occurred within urbanized open space;

TUOS $=$ total urbanized open space]

Extension (Ext.): Development of exterior open space took place between certain times periods. It is calculated by subtracting total urban area at a given time from the total urban area at present.

Numerical expression of Extension (Ext.):

$$
\begin{aligned}
& \text { Ext. }=\mathrm{TUA}_{\mathrm{p}}-\mathrm{TUA}_{\mathrm{t}} \\
& {\left[\mathrm{TUA}_{\mathrm{p}}=\right.\text { total urban area at present time; }} \\
& \left.\mathrm{TUA}_{\mathrm{t}}=\text { total urban area at a given time }\right] \\
& \text { Urban Fragmentation Index }(\mathrm{UFI})=\mathrm{ULR}+\mathrm{IR}+\mathrm{Ext}
\end{aligned}
$$

\section{Urban Climate}

Urban climate has the potential to impact infrastructure significantly, altering the environment, and affecting human health. In order to measure the urban climate, both spatial, and temporal measurements are recommended. A set of criteria and sub-criteria has been suggested (see Figure 3 and Table 3 ). Surface temperature map, remotely sensed thermal infrared technique; i.e., (i). Advanced Very High Resolution Radiometer (AVHRR), (ii). Heat Capacity Mapping Mission (HCMM) can be used for the experimentation.

The Urban Climate is an important parameter to measure ambient air temperature between cities and their surrounding rural areas (Grimmond et al., 2010). Through this indicator, the relationship between Vegetative Cover (VC), Water Body (WB), and Urban Heat Island (UHI) can be studied. Moreover, the urban climate must be compared, both spatially and temporally, with the degree of fragmentation. There are mainly two different types of UHI-air temperature UHI and surface UHI (Weng et al., 2004).

Heat island has inverse correlation with water body and vegetative cover. It is said that urban land without vegetation and with less water body contributes in generating UHI. Therefore, Urban Climate (UC) can be analyzed based on three different
TABLE 4 | Measuring scales of the indexes Urban Heat Island (UHI); Water Body (WB) and Vegetative Cover (VC) for urban climates.

\begin{tabular}{lccccc}
\hline Indexes & \multicolumn{5}{c}{ Scale } \\
\cline { 2 - 6 } & Excellent & Very Good & Good & Bad & Worst \\
& $\mathbf{5}$ & $\mathbf{4}$ & $\mathbf{3}$ & $\mathbf{2}$ & $\mathbf{1}$ \\
\hline UHI & Avg.T. +2 & Avg.T. +4 & Avg.T. +6 & Avg.T. +8 & Avg.T. +10 \\
WB & $3.5 \%$ & $3 \%$ & $2.5 \%$ & $2 \%$ & $<1.5 \%$ \\
VC & $25 \%$ & $20 \%$ & $15 \%$ & $10 \%$ & $5 \%$ \\
\hline
\end{tabular}

indexes-UHI, vegetative cover and water body. UC can be measured on the scale of 1 to 5 , where 1 indicates that UC is in the worst condition, while 5 represents an excellent UC (see Table 4). Moreover, to measure UC, above three indexes can be calculated separately and combined in the final calculation. Vegetative cover and water body can be measured in percentage.

A water body (WB) has the potential to reduce/lower the air temperature through evaporation and convection. A recent review conducted by Manteghi et al. (2015) analyzed the effect of water bodies on urban microclimate. A water body can act as a moisture source to reduce the surrounding temperature in an urban environment, and this cooling process is called the oasis effect (Potchter et al., 2008). Moreover, a water body has the potential to absorb heat without much temperature variation in the water body itself, which is called convection. The reason behind this effect is that water has highest specific heat capacity, and in order to absorb heat, water molecules move faster, which breaks hydrogen bonds; during this breakdown hydrogen bonds absorb this heat. In this research, WB includes rivers, ponds and lakes. Since little research has done focusing on the urban cooling potential of water bodies (Manteghi et al., 2015), this can be a future research area. Table 4 demonstrates how different components of urban climates can be quantified and measured.

Based on the above measuring scales of the indexes, the standardized values can be measured and the urban climate can be calculated as:

$$
\text { Urban Climate }(\mathrm{UC})=(\mathrm{VC}+\mathrm{WB}+\mathrm{UHI}) / 3
$$

\section{Vulnerability to Environmental Hazard}

Urban agglomeration has become extremely vulnerable to environmental hazards due to the increasing proportion of pollutions, population, and material assets in the urban region (Mcdonald et al., 2008). Environmental hazards such as floods, water scarcity, and air pollution are some of the challenges that need attention in measuring urban health (Brown, 2014). Suggested are to measure water and air pollution, and the frequency and intensity of natural disaster both temporally and spatially. The sample can be collected from different points in the urban area and will be tested in the laboratory. Moreover, an array of secondary data of water and air quality can be collected from respective departments.

Water pollution Index: Water samples need to be collected from rivers that are flowing through or near to an urban area. Samples can be collected from different points of the river. However, the main points need to be considered are (a) before 
TABLE 5 | Scales and degree of water pollution and how they are described in the water pollution index.

\begin{tabular}{|c|c|c|c|c|c|c|}
\hline Parameter & Classification & Clean & Slightly polluted & Moderate polluted & Polluted & Highly polluted \\
\hline Chemical Oxygen Demand - COD (mg/L) & & $5.88^{*}$ & 7.35 & 9.55 & 13.23 & $>13.23$ \\
\hline Dissolved Oxygen-DO (mg/L) & & $8^{*}$ & $6-7$ & $4-5$ & $2-3$ & 1 \\
\hline $\mathrm{Ph}$ & & $7^{\star}$ & $7 \pm 1$ & $7 \pm 2$ & $7 \pm 3$ & $7 \pm 4$ \\
\hline
\end{tabular}

(*Source: WHO).

TABLE 6 | Scales and values of different parameters of the air quality.

\begin{tabular}{|c|c|c|c|c|c|c|c|}
\hline Parameters & Values & Classification & Good & Moderate & Unhealthy & Very unhealthy & Hazardous \\
\hline $\mathrm{PM}_{10}(\mathrm{ug} / \mathrm{m} 3)$ & An AQI of 100 corresponds to $150 \mathrm{ug} / \mathrm{m3}$ & & & & & & \\
\hline $\mathrm{NO}_{2}(\mathrm{ppm})$ & An AQI of 100 corresponds to 0.50 ppm & & & & & & \\
\hline $\mathrm{SO}_{2}(\mathrm{ppm})$ & An AQl of 100 corresponds to $75 \mathrm{ppm}$ & & & & & & \\
\hline
\end{tabular}

(Source: US Environmental Protection Agency, USEPA, 2014).

entering to a city, (b) after crossing a city, and (c) some samples will be collected between a and b. Samples should be collected during normal flow of river water. Water quality ranged from 1 to 5 , where 5 stands for clean and pure water, whereas 1 denotes highly polluted water. Table 5 describes different levels of water quality and their evaluating criteria [between 5 (excellent/clean) and 1 (worst/highly polluted)].

The values can be standardized and the water quality index can be calculated as:

Water Quality Index $(\mathrm{WQI})=(\mathrm{BOD}+\mathrm{COD}+\mathrm{DO}+\mathrm{pH}) / 4$

Air Quality Index (AQI): Air quality can range from 0 to 500. Table 6 shows different scales of the condition of five different parameters of the air quality. Parameters selected for this AQI are highly sensitive for human health. If the combined index score more than 50 denotes are going to cause many health difficulties like heart and lung diseases for human beings of all ages. US Environmental Protection Agency (EPA) calculates the AQI for five major air pollutants regulated by the Clean Air Act: groundlevel ozone $\left(\mathrm{O}_{3}\right)$, particle pollution (also known as particulate matter, $\left.\mathrm{PM}_{10}\right)$, carbon monoxide $(\mathrm{CO})$, sulfur dioxide $\left(\mathrm{SO}_{2}\right)$, and nitrogen dioxide $\left(\mathrm{NO}_{2}\right)$. For each of these pollutants, EPA has established national air quality standards to protect public health. Ground-level ozone and airborne particles are the two pollutants that pose the greatest threat to human health. In many countries, various public and private entities have series of data on these parameters and they can easily be measured.

Although, the AQI have been classified in 5-6 scales and the values ranges between 1 and 500; they are again reclassified and scored between 1 and 5 scales to standardize for the proposed EII. This is important to make it standard with other indexes so that a combined integrity index can easily be calculated. Therefore, the standardize values of the parameters can be measured through the following equation:

Air Quality Index $(\mathrm{AQI})=\left(\mathrm{CO}+\mathrm{PM}_{10}+\mathrm{NO}_{2}+\mathrm{SO}_{2}+\mathrm{O}_{3}\right) / 5$

\section{Calculation of the Environmental Integrity Index (EII)}

Finally, an EII can be calculated from the results of the UFI, $\mathrm{UC}$, and the VEH. All the numbers are standardized, so they are comparable on the same scale. Here, all the indicators are mounted between 5 and 1 , where 5 denotes excellent and 1 indicates the worst condition. Therefore, the final EII will be calculated as:

Environmental Integrity Index EII $=(\mathrm{UFI}+\mathrm{UC}+\mathrm{VEH}) / 3$

\section{DISCUSSION AND CONCLUSIONS}

Apart from large urban facilities and lifestyles, rapid and poorly planned urbanization hinders environmental integrity. Inadequately managed urban expansion results in rapid urban sprawl, high consumption demand, pollution, and finally, environmental degradation. The proposed EII is an approach for assessing environmental condition of a highly complex urban area. Three main indicators have been selected for this indexlandscape fragmentation, urban climate, and vulnerability to an environmental hazard. These main indicators have several subindicators which have been quantified and integrated through standardization. The aim of this approach is to set a multiscaled, flexible, simple, adjustable and policy relevant index. The proposed indicator landscape fragmentation indicates the nature 
of alteration of urban land due to anthropogenic activities. The second indicator urban climate represents how land alteration affects water body and vegetation that results the increase of the urban heat. The third indicator, vulnerability to environmental hazard, calculates the state of urban air and water quality. The majority of the data for the proposed indicators are usually based on remotely sensed satellite data and other digitized data.

The EII is suitable for measuring environmental health in the rapidly growing and highly complex urban systems. The EII approach addresses natural stresses as well as the anthropogenic ones through the selected set of indicators. This capacity makes it unique from the ecological or biological integrity indexes (Paul, 2003). This measurement is particularly important for designing sustainable cities. Many rapidly developing urban areas are lacking specific measuring criteria, for example, in the Asia and African countries. Such easy to use index has potential use for those settings to ensure environmental integrity for sustainability as well as ensuring livable and healthy cities. However, issues of weighting schemes, uncertainties, scales, and the appropriate ways to interpret values should be taken into account while applying this EII (Demars, 2013; Marzin et al., 2014).

Multimetric indexes have been in use since the mid-20th century in the US and in central Europe (Paul, 2003). Indices for monitoring environmental integrity of the urban watersheds of many cities in the US have been experimented since 1996 which is in use through several modifications to till date (Clamann et al., 2013). However, their approach is not suitable for many regions of the developing countries due to lack of required data sets. Keeping these into mind, our approach considers the availability of datasets and are designed to be useful for those areas where a rich array of environmental datasets are not available, i.e., many Asian and African cities. Our approach is simple and easy to use, but this is the strength of this EII which, we presume, will make the index suitable for measuring environmental integrity

\section{REFERENCES}

Abdullah, S. A., and Nakagoshi, N. (2006). Changes in landscape spatial pattern in the highly developing state of Selangor, peninsular Malaysia. Landscape Urban Plan. 77, 263-275. doi: 10.1016/j.landurbplan.2005.03.003

Alam, M., Jérôme, D., and Messier, C. (2016). A framework towards a composite indicator for urban ecosystem services. Ecol. Indic. 60, 38-44. doi: 10.1016/j.ecolind.2015.05.035

Andreasen, J. K., O’Neill, R. V., Noss, R., and Slosser, N. C. (2001). Considerations for the development of a terrestrial index of ecological integrity. Ecol. Indic. 1, 21-35. doi: 10.1016/S1470-160X(01)00007-3

Barbour, M. T., Swietlik, W. F., Jackson, S. K., Courtemanch, D. L., Davis, S. P., and Yoder, C. O. (2000). Measuring the attainment of biological integrity in the USA: a critical element of ecological integrity. Hydrobiologia 422, 453-464. doi: 10.1023/A:1017095003609

Bell, S., and Morse, S. (2008). Sustainability Indicators: Measuring the Immeasurable? London: Earthscan.

BEQUEST (2000). Information Paper 5. Available online at: http://www.surveying. salford.ac.uk/bqextra

Borja, A., Ranasinghe, A., and Weisberg, S. B. (2009). Assessing ecological integrity in marine waters, using multiple indices and ecosystem components: challenges for the future. Mar. Pollut. Bull. 59, 1-4. doi: 10.1016/j.marpolbul.2008. 11.006 of these regions. Yet, the main limitations of this index is that not all the components of the environment are covered in the index, which increases the risk of missing some important indicators. In addition, this index has not been applied to an area or even utilized to compare areas to illustrate its use and perhaps even discover any inefficiencies. This is suggested in future works.

Lobdell et al. (2011) suggested an array of data sources for developing an environmental quality index (EQI), which may be helpful to monitor environmental quality and public health. This work is a significant contribution, however, it is limited to the human health purpose. Detail aspects of environmental integrity is not considered there and thus not suitable for long term sustainable urban environmental health decision making process. However, our approach describes a possible framework for developing an EII, which can be used as a guideline for uncontrolled and rapid urbanization, and a basis for environmental monitoring, evaluation and management purposes for urban and regional development. Moreover, it can be used in further research in local and regional urban planning, sustainable management, environmental monitoring, and assessment.

\section{AUTHOR CONTRIBUTIONS}

SS and MR have conceived the research, designed the experimental framework. SS initiated manuscript preparation, later MR fine tuned the manuscript. MR is supervisor, project leader, contributed in revisions and finalizing the manuscript, he is the corresponding author.

\section{FUNDING}

The authors thank the Universiti Kebangsaan Malaysia for financial assistance through the research fund DLP-2014-015.
Brown, L. A. (2014). The city in 2050: a kaleidoscopic perspective. Appl. Geogr. 49, 4-11. doi: 10.1016/j.apgeog.2013.09.003

Chen, B., and Wang, R. (2014). Integrated ecological indicators for sustainable urban ecosystem evaluation and management. Ecol. Indic. 47, 1-4. doi: 10.1016/j.ecolind.2014.09.020

Clamann, A., Richter, A., and Yeoman, E. (2013). Environmental Integrity Index: Phase I \& II (2011-2012) Watershed Summary Report. Austin, TX: Watershed Protection Department.

Cohen, B. (2006). Urbanization in developing countries: current trends, future projections, and key challenges for sustainability. Tech. Soc. 28, 63-80. doi: 10.1016/j.techsoc.2005.10.005

Davis, K. (1955). The origin and growth of urbanization in the world. Am. J. Sociol. 60, 429-437. doi: 10.1086/221602

Dawson, R., Hall, J., Barr, S. L., Batty, M., Bristow, A. L., Carney, S., et al. (2007). A Blueprint for the Integrated Assessment of Climate Change in Cities. Tyndall Working Papers 104, Tyndall Centre for Climate Change Research, University of East Anglia, Norwich, UK. p. 154.

Deakin, M., Huovila, P., Rao, S., Sunikka, M., and Vreeker, R. (2002). The assessment of sustainable urban development. Build. Res. Infor. 30, 95-108. doi: $10.1080 / 096132102753436477$

Demars, B. (2013). Uncertainties in biotic indicators and a corrigendum to: implications for biomonitoring. Ecol. Indic. 27, 44-47. doi: 10.1016/j.ecolind. 2012.11.003 
Dias, N., Curwell, S., and Bichard, E. (2014). The current approach of urban design, its implications for sustainable urban development. Procedia Econ. Finance 18, 497-504. doi: 10.1016/S2212-5671(14)00968-X

EEA (European Environment Agency) (2003). Europe's Environment: The Third Assessment. Copenhagen: EEA.

Forman, R. T. T. (1995). Land Mosaics: The Ecology of Landscapes and Regions. Cambridge, UK: Cambridge University Press.

Grimmond, C. S. B., Roth, M., Oke, T. R., Au, Y. C., Best, M., Betts, R., et al. (2010). Climate and more sustainable cities: climate information for improved planning and management of cities (producers/capabilities perspective). Procedia Environ. Sci. 1, 247-274. doi: 10.1016/j.proenv.2010.09.016

Hargiss, C. L. M., DeKeyser, E. S., Kirby, D. R., and Ell, M. J. (2008). Regional assessment of wetland plant communities using the index of plant community integrity. Ecol. Indic. 8, 303-307. doi: 10.1016/j.ecolind.2007.03.003

Heal, M. R., Heaviside, C., Doherty, R. M., Vieno, M., Stevenson, D. S., and Vardoulakis, S. (2013). Health burdens of surface ozone in the UK for a range of future scenarios. Environ. Int. 61, 36-44. doi: 10.1016/j.envint.2013.09.010

Heaviside, C., Cai, X.-M., and Vardoulakis, S. (2015). The effects of horizontal advection on the urban heat island in Birmingham and the West Midlands, United Kingdom during a heatwave. Q. J. R. Meteorol. Soc. 141, 1429-1441. doi: $10.1002 /$ qj. 2452

Holden, M., and Scerri, A. (2013). More than this: liveable Melbourne meets liveable Vancouver. Cities 31, 444-453. doi: 110.1016/j.cities.2012.07.013

Ichimura, M. (2003). "Urbanization, urban environment and land use: challenges and opportunities," in An Issue Paper, Presented at Asia-Pacific Forum for Environment and Development Expert Meeting (Guilin).

Karr, J. R. (1981). Assessment of biotic integrity using fish communities. Fisheries 6, 21-27. doi: 10.1577/1548-8446(1981)006<0021:AOBIUF > 2.0.CO;2

Karr, J. R., and Chu, E. W. (1999). Restoring Life in Running Waters: Better Biological Monitoring. Washington, DC: Island Press.

Karr, J. R., and Dudley, D. R. (1981). Ecological perspective on water quality goals. Environ. Manage. 5, 55-68. doi: 10.1007/BF01866609

Levrel, H., Kerbiriou, C., Couvet, D., and Weber, J. (2009). OECD pressurestate-response indicators for managing biodiversity: a realistic perspective for a French biosphere reserve. Biodivers. Conserv. 18, 1719-1732. doi: 10.1007/s10531-008-9507-0

Li, F., Liu, X., Hu, D., Wang, R., Yang, W., Li, D., et al. (2009). Measurement indicators and an evaluation approach for assessing urban sustainable development: a case study for China’s Jining City. Landscape Urban Plan. 90, 134-142. doi: 10.1016/j.landurbplan.2008.10.022

Li, X., Li, X., Woetzel, J., Zhang, G., and Zhang, Y. (2014). The China Urban Sustainability Index 2013. Beijing: The Urban China Initiative.

Lobdell, D. T., Jagai, J. S., Rappazzo, K., and Messer, L. C. (2011). Data sources for an environmental quality index: availability, quality, and utility. Am. J. Public Health 101, S277-S285. doi: 10.2105/ajph.2011.300184

Macmillan, A., Davies, M., Shrubsole, C., Luxford, N., May, N., Chiu, L. F., et al. (2016). Integrated decision-making about housing, energy and wellbeing: a qualitative system dynamics model. Environ. Health 15, 37. doi: 10.1186/s12940-016-0098-z

Manteghi, G., bin Limit, H., and Remaz, D. (2015). Water bodies an urban microclimate: a review. Mod. Appl. Sci. 9, 1-12. doi: 10.5539/mas.v9n6p1

Marzin, A., Delaigue, O., Logez, M., Belliard, J., and Pont, D. (2014). Uncertainty associated with river health assessment in varying environment: the case of a predictive fish-based index in France. Ecol. Indic. 43, 195-204. doi: 10.1016/j.ecolind.2014.02.011

Masakazu, I. (2003). "Urbanization, Urban environment and land use: challenges and opportunities," in Asia-Pacific Forum for Environment and Development, Expert Meeting (Guilin).

May, R., Rex, K., Bellini, L., Sadullah, S., Nishi, E., James, F., et al. (2000). UN habitat indicators database: evaluation as a source of the status of urban development problems and programs. Cities 17, 237-244. doi: 10.1016/S0264-2751(00)00016-0

Mcdonald, R. I., Kareiva, P., and Forman, R. T. T. (2008). The implications of current and future urbanization for global protected areas and biodiversity conservation. Biol. Conserv. 141, 1695-1703. doi: 10.1016/j.biocon.2008.04.025

Michael, F. L., Noor, Z. Z., and Figueroa, M. J. (2014). Review of urban sustainability indicators assessment-case study between Asian countries. Habitat Int. 44, 491-500. doi: 10.1016/j.habitatint.2014.09.006
Milman, A., and Short, A. (2008). Incorporating resilience into sustainability indicators: an example for the urban water sector. Global Environ. Change 18, 758-767. doi: 10.1016/j.gloenvcha.2008.08.002

Müller, F. (2005). Indicating ecosystem and landscape organisation. Ecol. Indic. 5, 280-294. doi: 10.1016/j.ecolind.2005.03.017

Müller, F., Hoffmann-Kroll, R., and Wiggering, H. (2000). Indicating ecosystem integrity-theoretical concepts and environmental requirements. Ecol. Model. 130, 13-23. doi: 10.1016/S0304-3800(00)00210-6

Newman, P., and Kenworthy, J. (1999). Sustainability and Cities: Overcoming Automobile Dependence. Washington, DC: Island Press.

Niemeijer, D., and de Groot, R. S. (2008). A conceptual framework for selecting environmental indicator sets. Ecol. Indic. 8, 14-25. doi: 10.1016/j.ecolind.2006.11.012

Nieuwenhuijsen, M. J. (2016). Urban and transport planning, environmental exposures and health-new concepts, methods and tools to improve health in cities. Environ. Health 15, 38. doi: 10.1186/s12940-016$0108-1$

OECD (Organization of Economic Cooperation and Development). (1994). Environmental Indicators. OECD Core Sets. Paris: OECD.

Omar, D. (2009). Urban form and sustainability of a hot humid City of Kuala Lumpur. Euro. J. Soc. Sci. 8, 353-359.

Paul, J. F. (2003). Developing and applying an index of environmental integrity for the US Mid-Atlantic region. J. Environ. Manage. 67, 175-185. doi: 10.1016/S0301-4797(02)00206-2

Porio, E. (2014). Sustainable development goals and quality of life targets: insights from metro manila. Curr. Sociol. Monogr. 63, 244-260. doi: $10.1177 / 0011392114556586$

Potchter, O., Goldman, D., Kadish, D., and Iluz, D. (2008). The oasis effect in an extremely hot and arid climate: the case of southern Israel. J. Arid Environ. 72, 1721-1733. doi: 10.1016/j.jaridenv.2008.03.004

Ranhagen, U., and Groth, K. (2012). The Symbiocity Approach: A Conceptual Framework for Sustainable Urban Development. Stockholm: SKL International.

Reza, M. I. H. (2014a). Importance and considerations to develop a composite index of ecological integrity for ecological management. Int. J. Ecol. Dev. 28, 32-48. Available online at: http://www.ceser.in/ceserp/index.php/ijed/article/ view/1804

Reza, M. I. H. (2014b). Measuring forest fragmentation in the protected area system of a rapidly developing Southeast Asian tropical region. Sci. Postprint 1:e00030. doi: 10.14340/spp.2014.09A0001

Reza, M. I. H., and Abdullah, S. A. (2011). Regional index of ecological integrity: a need for sustainable management of natural resources. Ecol. Indic. 11, 220-229. doi: 10.1016/j.ecolind.2010.08.010

Roche, M. Y., Lechtenbohmer, S., Fischedick, M., Grone, M.-C., Xia, C., and Dienst, C. (2014). Concepts and methodologies for measuring the sustainability of cities. Annu. Rev. Environ. Res. 39, 519-547. doi: 10.1146/annurev-environ012913-101223

Rydin, Y., Bleahu, A., Davies, M., Dávila, J. D., Friel, S., De Grndis, G., et al. (2012). Shaping cities for health: complexity and the planning of urban environments in the 21st century. Lancet 379, 2079-2108. doi: 10.1016/S0140-6736(12)60435-8

Salmond, J. A., Tadaki, M., Vardoulakis, S., Arbuthnott, K., Coutts, A., Demuzere, M., et al. (2016). Health and climate related ecosystem services provided by street trees in the urban environment. Environ. Health 15, 36. doi: 10.1186/s12940-016-0103-6

Shamsuddin, S., and Rashid, A. A. (2013). "Malaysian urban rural national indicators network on Sustainable development (MURNInets)," The 43rd Annual Conference of the Urban Affairs Association (San Francisco, CA). Available online at: https://www.academia.edu/3369337/MALAYSIAN_ URBAN_RURAL_NATIONAL_INDICATORS_NETWORK_ON_ SUSTAINABLE_DEVELOPMENT_MURNInets_viewed 25 April 2016.

Sridhar, K. S., and Wan, G. (2014). Urbanization in Asia: Governance, Infrastructure and the Environment. Springer Science \& Business Media. doi: 10.1007/978-81-322-1638-4

Tanguay, G. A., Rajaonson, J., Lefebvre, J.-F., and Lanoie, P. (2010). Measuring the sustainability of cities: an analysis of the use of local indicators. Ecol. Indic. 10, 407-418. doi: 10.1016/j.ecolind.2009.07.013

Tulloch, V. J. D., Tulloch, A. I. T., Visconti, P., Halpern, B. S., Watson, J. E. M., Evans, M. C., et al. (2015). Why do we map threats? Linking threat mapping 
with actions to make better conservation decisions. Front. Ecol. Environ. 13, 91-99. doi: 10.1890/140022

UN Habitat (2009). Urban Indicators Guidelines; Better Information, Better Cities: Monitoring the Habitat Agenda and the Millennium Development Goals Slums Target. Nairobi: UN Habitat.

United Nations (2012). World Urbanization Prospects: The 2011 Revision, Highlights. New York, NY: Department of Economic and Social Affairs, Population Division, UN.

United Nations (2014). World Urbanization Prospects: The 2014 Revision, Highlights. New York, NY: Department of Economic and Social Affairs, Population Division, UN.

United Nations Development Programmes (2006). Making Progress on Environmental Sustainability. United Nations. Available online at: http://www. droughtmanagement.info/literature/UNDP_making_progress_environmental_ sustainability_2006.pdf (Accessed April 29, 2016).

USEPA (US Environmental Protection Agency) (2014). AQI Air Quality Index: A Guide to Air Quality and Your Health. North Carolina: EPA. Available online at: https://www3.epa.gov/airnow/aqi_brochure_02_14.pdf

Vardoulakis, S., Dear, K., and Wilkinson, P. (2016). Challenges and opportunities for urban environmental health and sustainability: the HEALTHYPOLIS initiative. Environ. Health 15, 30. doi: 10.1186/s12940-0160096-1

Vardoulakis, S., Dimitroulopoulou, C., Thornes, J., Lai, K. M., Taylor, J., Myers, I., et al. (2015). Impact of climate change on the domestic indoor environment and associated health risks in the UK. Environ. Int. 85, 299-313. doi: 10.1016/j.envint.2015.09.010

Weng, Q., Lu, D., and Schubring, J. (2004). Estimation of land surface temperature-vegetation abundance relationship for urban heat island studies. Rem. Sens. Environ. 89, 467-483. doi: 10.1016/j.rse.2003.11.005
Westra, L., Miller, P., Karr, J. R., Rees, W. E., and Ulanowicz, R. E. (2000). "Ecological integrity and the aims of the global integrity project," in Ecological Integrity: Integrating Environment, Conservation, and Health, eds D. Pimentel, L. Westra, and R. F. Noss (Washington, DC: Inland Press), 19-41.

Woods, M., Crabbe, H., Close, R., Studden, M., Milojevic, A., Leonardi, G., et al. (2016). Decision support for risk prioritisation of environmental health hazards in a UK city. Environ. Health 15, 29. doi: 10.1186/s12940-0160099-y

Yigitcanlar, T., O'Connor, K., and Westerman, C. (2008). The making of knowledge cities: Melbourne's knowledge-based urban development experience. Cities 25, 63-72. doi: 10.1016/j.cities.2008.01.001

Zavadskas, E. K., Kaklauskas, A., and Saparauskas, J. (2005). Sustainable urban development and web-based multiple criteria analysis. Found. Civil Environ. Eng. 6, 217-226. Available online at: https://www.infona.pl/resource/bwmeta1. element.baztech-article-BPP1-0059-0064

Zhou, J., Shen, L., Song, X., and Zhang, X. (2015). Selection and modeling sustainable urbanization indicators: a responsibility-based method. Ecol. Indic. 56, 87-95. doi: 10.1016/j.ecolind.2015.03.024

Conflict of Interest Statement: The authors declare that the research was conducted in the absence of any commercial or financial relationships that could be construed as a potential conflict of interest.

Copyright (c) 2016 Shathy and Reza. This is an open-access article distributed under the terms of the Creative Commons Attribution License (CC BY). The use, distribution or reproduction in other forums is permitted, provided the original author(s) or licensor are credited and that the original publication in this journal is cited, in accordance with accepted academic practice. No use, distribution or reproduction is permitted which does not comply with these terms. 